\title{
Access Pricing in the Postal Sector: Theory and Simulations
}

\author{
Philippe De Donder ${ }^{1}$ \\ University of Toulouse (IDEI and CNRS-GREMAQ)
}

March 2006

${ }^{1} 21$ allées de Brienne, 31000 Toulouse, France. Email: dedonder@cict.fr. Tel.: +33.561.128.603. Fax.: +33.561.128.637. 


\begin{abstract}
This paper studies a theoretical model aimed at assessing the optimal access charges and retail prices in the postal sector. It takes explicitly into account three main characteristics of the postal sector: the ability of entrants to bypass the incumbent's delivery network; the imposition on the incumbent, but not on entrants of universal service obligations; and the provision of access to both competitors and customers. The paper first develops analytical formulations of the optimal access charges and the incumbent's end-to-end retail price. It then presents calibrated results illustrating the impact on prices and welfare of various scenarios.
\end{abstract}

Keywords: Ramsey prices, bypass, consumer direct access, worksharing, displacement ratio. 


\section{Introduction}

The liberalization of network industries, starting with airlines, telecommunications and energy, has generated an extensive literature on mandatory access to parts of an incumbent's network. ${ }^{1}$ Although all these sectors are often regrouped under the heading of network industries, any mandatory access policy should take into account the specific characteristics of each of these sectors. The objective of this paper to develop an access pricing model that takes explicitly into account the main characteristics of the postal sector.

The postal sector exhibits a unique mix of characteristics relevant for access pricing regulation. First, the bottleneck in this industry is the delivery network: ${ }^{2}$ due to significant economies of scale in delivery ${ }^{3}$ (whose costs represent roughly $50 \%$ of the total postal costs), entrants need access to at least part of the incumbent's delivery network. More precisely, it may be economically feasible for the entrant to deliver mail in high density areas (as in Sweden with Citymail for instance), but not in low density ones. Second, the incumbent is subject to universal service obligations while entrants are not: the incumbent (which I will call from now on the universal service provider, or USP) is obliged to deliver mail to all locations for the same price while satisfying minimum quality standards. Ubiquity translates into the existence of a fixed cost for the incumbent, which has to build a network of delivery offices and level of staff within them, which is largely a fixed cost. Uniform pricing, like selective bypass, requires the development of a model with at least two delivery areas.

While these two characteristics may be shared with other network industries, a

\footnotetext{
${ }^{1}$ See for instance Laffont and Tirole(2000), Armstrong (2001, 2002) and Armstrong et al. (1996).

${ }^{2} \mathrm{~A}$ vertically integrated postal operator performs the following activities: collection, local transportation, outward sortation, long haul transportation, inward sortation, transportation to post office, and then delivery. There is little if any evidence that collection, transportation, and sortation present significant economies of scale or sunk costs (Panzar 2002) or that they could qualify as essential facilities (Crew and Kleindorfer 2002).

${ }^{3}$ See Rogerson et al. (1993) and Cazals et al. (2004).
} 
third one is very much restricted to the postal sector: access to the delivery network is provided not only to competitors but also to clients, in the form of "work-sharing", by which large senders who pre-sort their mail and bring it directly to a mail processing center receive a rebate on the full retail price. Work-sharing (which I call here CDA for customer direct access) is very similar to access by entrants, since in both cases the incumbent sells some products using all of its network (regular mail) and other products using only part of this network (the work-shared mail).

I develop a theoretical model embedding these elements in order to look for the optimal access charges and USP's retail price formulas. I then calibrate the model and resort to numerical simulations to obtain results that the mere exploitation of first order conditions cannot supply. The main results I obtain are as follows:

The optimal access charges ${ }^{4}$ are composed of three parts: the delivery cost, a displacement term, and a Ramsey term. The displacement term generalizes Armstrong (2002) and measures how much end-to-end (E2E) demand the USP loses when one unit of access is provided. Optimal CDA and entrant's access charges need not be equal even without a Ramsey term and with identical delivery costs. I provide a very intuitive condition under which the first is lower than the latter. The optimal uniform retail price for the USP is a weighted average of its costs in the two markets. The uniform pricing constraint prevents pricing of access at marginal cost (for both delivery areas) even in the absence of any break-even constraint. The optimal price formula puts less weight on an area when access is supplied to it than when it is not.

Turning to numerical simulations, I first obtain that welfare is increased by adding both CDA and the entrant's good when bypass is unavailable to the entrant. On the other hand, allowing for bypass decreases welfare below its monopoly level because the USP reacts to the loss of volumes delivered in the urban area (where the entrant bypasses the USP delivery network) by increasing its prices. I also look at the regulator's

\footnotetext{
${ }^{4}$ I.e., the access charges that maximize the (possibly weighted) sum of consumer surplus and operators' profits, subject to the USP breaking even.
} 
objectives other than pure welfare maximization. I first show that, if the regulator puts enough weight on consumers' surplus compared to operators' profit, the result does not depend on the precise weight chosen. I also show that the impact of increasing the weight put on one category of consumers (urban or rural) on the USP E2E price is not symmetrical, with this price increasing with the weight put on urban consumers and decreasing with the weight put on rural ones. Finally, I study the situation where the regulator minimizes the USP E2E price and show that this price is higher when bypass is available than under monopoly.

\section{Related literature}

This paper is related to the theoretical literature on access pricing and its applications to the postal industry. The two papers closest to mine are Armstrong (2001) and Armstrong et al. (1996). Armstrong (2001) focuses on the consequences of bypass and universal service on access pricing. The structure of demands that it posits is much simpler than the one developed in this paper, with homogenous goods and inelastic demands. The framework developed in Armstrong et al. (1996) does not encompass universal service obligations but allows for bypass and multiple heterogenous products.

The analysis developed here combines aspects of both papers, since it embodies universal service obligations, bypass, and heterogenous goods. It differs from these papers on several grounds. First, I introduce both access to entrants and access provided to customers (CDA), and I solve for all optimal access charges and retail prices simultaneously. Second, I allow for regulator's objectives other than the maximization of unweighted welfare (such as the minimization of the USP retail price). Third, my paper calibrates a model of the sector to shed light on whether bypass actually occurs or not, the contribution to welfare of both CDA and the entrant's good, and the consequences of modifying the regulator's objective.

Previous papers have applied access pricing theory to the postal sector (such as 
Billette et al. (2003b) and Crew and Kleindorfer (2002)), but few consider CDA. Billette et al. (2004) explicitly consider both CDA and entrant's access at the same time. In contrast to my paper, they model only one delivery area without bypass possibility for the entrant. Cazalda (2005) models access to entrants and CDA but deals with a different regulatory and informational framework. He concentrates on non-local letters for which the incumbent has the monopoly of delivery and on the sorting activities, with customers differing in preparation costs.

Panzar (2004) develops a model where the incumbent offers an end-to-end (E2E) product to two areas, differing in delivery cost, for the same uniform price. In addition to the entrant providing E2E services to customers, a second group of fringe competitors supplying downstream delivery bypass services to the incumbent in the low cost area. A central concept is the availability of piecemeal bypass, which allows mailers to bypass totally the incumbent by combining pre-sortation with the delivery services of competing suppliers. The main message of the paper is that piecemeal bypass poses more problems than end-to-end bypass.

A major difference with most papers cited above is that I go beyond the analytical solving of the model and resort to numerical simulations in order to give qualitative results on the impact of the access policy on welfare levels. A first step in this direction is presented in De Donder et al. (2004). The main differences with that paper are as follows. First, our previous paper was more focused on numerical simulations while the current one tries to present carefully the optimality conditions and to interpret them. Second, the previous paper required that the access charges be the same for the entrants and for large customers, a restriction we relax here. Third, I also study here other regulator's objectives. Fourth, these differences translate into other simulations results reported in the current paper.

I develop the model in the next section and study the optimal pricing policy (including access) in section 4 . Section 5 calibrates the model and shows numerical simulations. 
Section 6 concludes.

\section{The model}

I consider two categories of postal operators: the universal service provider (USP) and a set of entrants that act as a competitive fringe. The assumption of a competitive fringe is motivated by the fact that postal activity exhibits few sunk costs, except perhaps in delivery. Moreover, roughly $80 \%$ of delivery costs are labor costs, and one can argue that such costs are more flexible for the entrant than for the incumbent (for instance because they face less pressure from their owners to keep high employment levels).

Both the USP and the entrants offer a single product (average mail), which can be sent to the rural or to the urban area. The USP has to serve both markets at a uniform price. The entrants are not subject to a uniform service obligation and choose which market (urban and/or rural) to serve and at which price. In addition to those two mail services, customers (senders) can directly access the USP's delivery network. I call this possibility customers' direct access (CDA) and model it as a third service that can be used by a representative consumer wishing to send mail. The three services offered (the USP's, the entrants', and CDA) may differ on several accounts: in quality (reliability, speed of delivery) or in terms of ease of access to each collection network, for instance. I assume that they are imperfect substitutes in any given area, and that demands are independent across areas, with the price in one area not affecting the number of letters sent to the other one.

I separate the postal activity into two segments: one for collection-sortation-transportation, and one for delivery. Both operators are active in the first segment. The USP delivers its letters in both markets, while the entrant can choose whether to deliver itself or to access the USP's delivery network. I restrict myself to linear access pricing, so that the entrant delivers itself if its unit delivery cost is lower than the access charge. Moreover, if the access charge is higher than the full retail price of the USP, the entrant 
prefers remailing its letters through the USP rather than using access.

The representative customer may also access directly the USP delivery network. In that case, he bears a preparation cost in order to presort his mail and to bring it to the interconnection point on the USP network and then pays an access charge. We assume that the USP may post different access prices for the entrant and for CDA.

I now introduce the notation used in the paper. We denote by an upperscript $I$ variables pertaining to the E2E mail services of the USP, by $E$ to the entrant's mail services, and by $D$ to CDA. We use the subscript $U$ for the urban market and $R$ for the rural market.

The net surplus that the representative agent gets from sending mail to area $j$ is given by

$$
V_{j}\left(q_{j}^{I}, q_{j}^{E}, q_{j}^{D}\right)-p q_{j}^{I}-p_{j}^{E} q_{j}^{E}-p_{j}^{D} q_{j}^{D}
$$

where $q_{j}^{i}$ denotes the quantity of mail of type $i \in\{I, E, D\}$ for delivery in area $j \in$ $\{U, R\}, p$ denotes the USP uniform retail price, $p_{j}^{E}$ stands for the entrant's retail price for mail delivered to area $j$, and the total unit price of CDA is $p_{j}^{D}=a_{j}^{D}+k$, with $a_{j}^{D}$ the CDA charge for delivery to area $j$ (alternatively, $p-a_{j}^{D}$ measures the corresponding work-sharing discount) and $k$ is the preparation cost. ${ }^{5}$ Note that the sender's surplus does not depend on the method that the entrant chooses to deliver mail: we assume that the "make or buy" decision by the entrant does not affect the characteristics of the good for the consumers. In other words, the differentiation between the entrants' and the incumbent's mail product is to be found in the upstream activity (collection, transportation and sortation) rather than in delivery. This is a strong assumption that we would like to weaken in future research.

Maximization of net surplus by the representative sender gives the demand functions for the three kinds of mail sent to area $j: q_{j}^{D}\left(p, p_{j}^{E}, p_{j}^{D}\right)$ for $\mathrm{CDA}, q_{j}^{I}\left(p, p_{j}^{E}, p_{j}^{D}\right)$ for the

\footnotetext{
${ }^{5}$ The function $V_{j}($.$) is non-separable in its 3$ arguments. The preparation cost $k$ does not depend on the delivery area.
} 
USP's good, and $q_{j}^{E}\left(p, p_{j}^{E}, p_{j}^{D}\right)$ for the entrant, with negative own price derivatives and positive cross price derivatives.

The function $z_{j}^{E}\left(p, p_{j}^{E}, p_{j}^{D}, a_{j}^{E}, d_{j}^{E}\right)$ gives the number of letters effectively delivered by the entrant in area $j \in\{U, R\}$. It is a function of the three competing mail services' prices (which jointly determine the demand faced by the entrant) and of the unit access price $a_{j}^{E}$ and entrant's delivery cost $d_{j}^{E}$ to area $j$ (which jointly determine whether the entrant delivers by itself or uses access to the USP network). We then obtain as $q_{j}^{E}\left(p, p_{j}^{E}, p_{j}^{D}\right)-z_{j}^{E}\left(p, p_{j}^{E}, p_{j}^{D}, a_{j}^{E}, d_{j}^{E}\right)$ the amount of access to area $j$ sold by the USP to the entrant. ${ }^{6}$

The universal service obligation results in a global fixed cost for the USP, which is denoted by $F$. The entrant is not subject to such obligations, and I thus consider that all of its costs are variable in the long run. Both operators face a (constant) marginal collection cost of $c^{i}, i \in\{I, E\}$. The collection cost is independent of the area that the letter should be delivered to, but may differ from one operator to the other. As for the delivery costs, both operators $i \in\{I, E\}$ have a constant marginal cost of delivery to area $j \in\{U, R\}$, which is denoted by $d_{j}^{i}$.

The USP's profit is now given by

$$
\begin{aligned}
\Pi^{I}= & \left(p-c^{I}\right)\left(q_{U}^{I}+q_{R}^{I}\right)-d_{U}^{I} q_{U}^{I}-d_{R}^{I} q_{R}^{I}-F \\
& +\left(a_{U}^{E}-d_{U}^{I}\right)\left(q_{U}^{E}-z_{U}^{E}\right)+\left(a_{U}^{D}-d_{U}^{I}\right) q_{U}^{D} \\
& +\left(a_{R}^{E}-d_{R}^{I}\right)\left(q_{R}^{E}-z_{R}^{E}\right)+\left(a_{R}^{D}-d_{R}^{I}\right) q_{R}^{D}
\end{aligned}
$$

where the first line gives the profit made by the USP on its own E2E product while the second (third) line is the profit made selling both kinds of access to the urban (rural) area. The entrant's profit is given by

$$
\Pi^{E}=\left(p_{U}^{E}-c^{E}\right) q_{U}^{E}+\left(p_{R}^{E}-c^{E}\right) q_{R}^{E}-d_{U}^{E} z_{U}^{E}-d_{R}^{E} z_{R}^{E}
$$

\footnotetext{
${ }^{6}$ To simplify the exposition, we drop the arguments of the functions $q_{j}^{i}$ and $z_{j}^{E}$ in most of what follows.
} 


$$
-a_{U}^{E}\left(q_{U}^{E}-z_{U}^{E}\right)-a_{R}^{E}\left(q_{R}^{E}-z_{R}^{E}\right)
$$

with $0 \leq z_{j}^{E} \leq q_{j}^{E}$ and $a_{j}^{E} \leq p, \quad j \in\{U, R\}$. Maximization of the entrant's profit yields

$$
z_{j}^{E}\left(p, p_{j}^{E}, p_{j}^{D}, a_{j}^{E}, d_{j}^{E}\right)=\left\{\begin{array}{c}
0 \text { if } d_{j}^{E} \geq a_{j}^{E} \\
q_{j}^{E}\left(p, p_{j}^{E}, p_{j}^{D}\right) \text { if } d_{j}^{E}<a_{j}^{E},
\end{array}\right.
$$

that is, the entrant delivers itself only if it is strictly cheaper to do so rather than using access to the USP delivery network. Recall that the entrant acts as a competitive fringe, so that we have $p_{j}^{E}=c^{E}+\min \left(d_{j}^{E}, a_{j}^{E}\right)$.

\section{Optimal access charges and USP retail price}

In most of the paper, I assume that the regulator's objective is to maximize a weighted sum of postal operators' profits and consumers' net surpluses. I normalize the weight put on operators' profit to one and use $w_{j}$ to denote the weight put on net consumers' surplus in area $j\left(w_{j} \geq 0\right)$. I look for the optimal access charges and USP retail price, - i.e., access charges $a_{U}^{E}, a_{R}^{E}, a_{U}^{D}, a_{R}^{D}$, and price $p$ that simultaneously maximize total welfare $W$ under the constraint that the USP profit is non-negative $\left(\Pi^{I} \geq 0\right)$ and that $a_{j} \leq p, \quad j \in\{U, R\}:$

$$
\underset{a_{U}^{E}, a_{R}^{E}, a_{U}^{D}, a_{R}^{D}, p}{M a x} \quad W=\sum_{j=\{U, R\}} w_{j}\left(V_{j}\left(q_{j}^{I}, q_{j}^{E}, q_{j}^{D}\right)-p q_{j}^{I}-p_{j}^{E} q_{j}^{E}-p_{j}^{D} q_{j}^{D}\right)+\Pi^{I}+\Pi^{E}
$$

such that

$$
\begin{aligned}
\Pi^{I} & \geq 0 \\
a_{j}^{i} & \leq p, \quad j \in\{U, R\}, j \in\{E, D\} .
\end{aligned}
$$

I concentrate on the most interesting case, where the access charge paid by the entrant is lower than its delivery cost $\left(a_{j}^{E} \leq d_{j}^{E}\right)$, in which case, $z_{j}^{E}=0, p_{j}^{E}=c^{E}+a_{j}^{E}$. The first-order conditions for the optimal value of the access charges are

$$
a_{j}^{E}=d_{j}^{I}+\left(p-c^{I}-d_{j}^{I}\right) \sigma_{j}^{I E}+\left(a_{j}^{D}-d_{j}^{I}\right) \sigma_{j}^{D E}+\frac{1+\lambda-w_{j}}{1+\lambda}\left|\frac{a_{j}^{E}}{\varepsilon_{j}^{E}}\right|, j=\{U, R\}
$$




$$
a_{j}^{D}=d_{j}^{I}+\left(p-c^{I}-d_{j}^{I}\right) \sigma_{j}^{I D}+\left(a_{j}^{E}-d_{j}^{I}\right) \sigma_{j}^{E D}+\frac{1+\lambda-w_{j}}{1+\lambda}\left|\frac{a_{j}^{D}}{\varepsilon_{j}^{D}}\right|, j=\{U, R\}
$$

where $\lambda$ is the Lagrange multiplier associated with the USP's budget constraint,

$$
\sigma_{j}^{i k}=-\frac{\partial q_{j}^{i} / \partial p_{j}^{k}}{\partial q_{j}^{k} / \partial p_{j}^{k}}, i=\{I, D, E\}, j=\{U, R\}, k=\{D, E\}, i \neq k,
$$

and

$$
\varepsilon_{j}^{k}=\frac{\partial q_{j}^{k} / \partial a_{j}^{k}}{a_{j}^{k} / q_{j}^{k}}, j=\{U, R\}, k=\{D, E\}
$$

is the direct price elasticity of the demand for good $j$.

Similarly, the optimal value of the USP retail price is obtained from the following first-order condition

$$
\begin{aligned}
0= & (1+\lambda)\left\{\left(p-c^{I}-d_{U}^{I}\right) \frac{\partial q_{U}^{I}}{\partial p}+\left(a_{U}^{E}-d_{U}^{I}\right) \frac{\partial q_{U}^{E}}{\partial p}+\left(a_{U}^{D}-d_{U}^{I}\right) \frac{\partial q_{U}^{D}}{\partial p}\right. \\
& \left.+\left(p-c^{I}-d_{R}^{I}\right) \frac{\partial q_{R}^{I}}{\partial p}+\left(a_{R}^{E}-d_{R}^{I}\right) \frac{\partial q_{R}^{E}}{\partial p}+\left(a_{R}^{D}-d_{R}^{I}\right) \frac{\partial q_{R}^{D}}{\partial p}\right\} \\
& +\left(1+\lambda-w_{U}\right) q_{U}^{I}+\left(1+\lambda-w_{R}\right) q_{R}^{I} .
\end{aligned}
$$

Although these equations are not independent and must be satisfied simultaneously, I first proceed as in Armstrong et al. (1996) by studying them separately, beginning with the optimal access charge formulas (1) and (2). I first assume that $\lambda=0$ and $w_{j}=1$ (corresponding to the case of unweighted welfare maximization without profit constraint), which allows me to concentrate on the first three elements of equations (1) and (2). First observe that marginal cost pricing of access is required if and only ${ }^{7}$ if the incumbent's E2E good is also priced at marginal cost $\left(p=c+d_{j}^{I}\right)$. In that case, the access charges in a given region $j$ would be the same for the entrant and for $\mathrm{CDA}$, since the delivery cost is the same in both cases $\left(a_{j}^{E}=a_{j}^{D}=d_{j}^{I}\right)$. The uniform pricing requirement prevents this situation from occurring as soon as delivery costs

\footnotetext{
${ }^{7} \mathrm{I}$ exclude the case where $\sigma^{I E}=\sigma^{I D}=0$, since it would mean that the demand for the USP E2E service is independent of the price of both access goods.
} 
vary across delivery areas $\left(d_{U}^{I} \neq d_{R}^{I}\right)$. We see here the first impact of the uniform pricing requirement: it prevents marginal cost pricing of the incumbent E2E product in all regions and, by a Lipsey-Lancaster contagion effect, it also prevents marginal cost pricing of the access charges.

Let me then concentrate on the optimal entrant's access charge formula (1), since the same analysis holds, mutatis mutandis, for the CDA charge. With the competitive fringe assumption, an increase in this access charge increases the entrant's retail price by the same amount. The access charge then impacts not only the quantity of the entrant's good, but also the quantity of CDA and of the incumbent's E2E good. This impact on good $i=\{I, D\}$ depends on the displacement ratio $\sigma_{j}^{i E}$, which measures the substitutability between good $i$ and the entrant's good - i.e., by how much the demand for good $i$ decreases when one more unit of access is provided to the entrant. Multiplying this displacement ratio by the difference between the incumbent's price for good $i$ and its marginal cost for providing this good, one obtains the USP's total lost profit (on the retail market and on the market for CDA) caused by providing access to the entrant.

In other terms, the optimal access charge is in essence an ECPR (efficient component pricing rule) formula, since it is the sum of the cost of providing access and of the USP's lost profit caused by providing access. In the case where the products offered by the entrant and by the USP are perfect substitutes, the ECPR boils down to the margin (or net avoided) rule, where the USP makes the same margin when providing access to the entrant as when selling its own E2E product. The reader can check that this is the case here, with $a_{j}^{E}=p-c^{I}$ if and only if $\sigma_{j}^{I E}=1$ and $\sigma_{j}^{D E}=0$ - i.e., if each letter sent through the entrant simply displaces one E2E USP letter and has no impact on the amount of CDA.

The ECPR rule has many appealing properties. First, the bottleneck owner has no incentives to foreclose or degrade access to its network, since it is perfectly compensated for any profit forgone when providing access. Second, when the bottleneck owner and 
potential competitors offer perfect substitutes, ECPR guarantees that only efficient competitors will enter.

On the other hand, the ECPR has been criticized on various grounds (see Economides and White (1995) and Arsmtrong (2002) among others). First, if the retail price of the product sold by the bottleneck owner incorporates a monopolist's markup, the ECPR formula protects this monopoly rent and the resulting allocative inefficiency. Observe that we do not face this problem here, since the USP retail price is regulated and set at its welfare maximizing level. Second, in the general case of economies of scale in the production of the bottleneck service, the ECPR formula will in general not coincide with the optimal second-best access pricing formula. This criticism holds here, since the USP network cost incorporates a fixed cost. The ECPR formula has then to be modified by the addition (in equations (1) and (2)) of the product of a Ramsey term (inversely proportional to the direct price elasticity of the demand for access by the entrant) by the ratio $\left(1+\lambda-w_{j}\right) /(1+\lambda)$. This ratio increases with the shadow price of the USP profit constraint $(\lambda)$ and decreases with the weight being put by the regulator on the consumers' surplus in area $j$. It is easy to obtain well-known results for special cases of $\lambda$ and $w_{j}$, such as unweighted welfare maximization $(w=1, \lambda>0$, ratio $=\lambda /(1+\lambda))$, weighted welfare maximization without profit constraint $\left(\lambda=0, w>0\right.$, ratio $\left.=1-w_{j}\right)$, or even profit maximization $(w=0$, ratio=1). Note that, if the weight is $w$ larger than $1+\lambda$, the mark-up becomes negative.

I now go beyond the segmented analysis of the individual access charge optimality equations (1) and (2) by solving them simultaneously to obtain:

$$
\begin{aligned}
& a_{j}^{E}=d_{j}^{I}+\left(p-c^{I}-d_{j}^{I}\right) \sigma_{j}^{E}+\frac{1+\lambda-w_{j}}{1+\lambda} \frac{\left|\frac{a_{j}^{E}}{\varepsilon_{j}^{E}}\right|+\sigma_{j}^{D E}\left|\frac{a_{j}^{D}}{\varepsilon_{j}^{D}}\right|}{1-\sigma_{j}^{D E} \sigma_{j}^{E D}}, \\
& a_{j}^{D}=d_{j}^{I}+\left(p-c^{I}-d_{j}^{I}\right) \sigma_{j}^{D}+\frac{1+\lambda-w_{j}}{1+\lambda} \frac{\left|\frac{a_{j}^{D}}{\varepsilon_{j}^{D}}\right|+\sigma_{j}^{E D}\left|\frac{a_{j}^{E}}{\varepsilon_{j}^{E}}\right|}{1-\sigma_{j}^{D E} \sigma_{j}^{E D}},
\end{aligned}
$$


where

$$
\sigma_{j}^{E}=\frac{\sigma_{j}^{I E}+\sigma_{j}^{I D} \sigma_{j}^{D E}}{1-\sigma_{j}^{D E} \sigma_{j}^{E D}}
$$

and

$$
\sigma_{j}^{D}=\frac{\sigma_{j}^{I D}+\sigma_{j}^{I E} \sigma_{j}^{E D}}{1-\sigma_{j}^{D E} \sigma_{j}^{E D}} .
$$

As above, I first concentrate on the first two terms of (4) and (5). The second term is composed of a displacement ratio whose formula is made more complex by simultaneous interactions between the three substitute goods. This displacement ratio takes into account three kinds of displacements: direct and indirect effects between USP E2E product and access products, and feedback effects between the two access products.

The numerator in (6) and (7) adds direct and indirect displacements. The direct impact, $\sigma^{I j}$, is the displacement of USP E2E service by access service $j$, as in (1) or in Armstrong (2002). The indirect impact is the displacement of USP 2E2 service by the access service $j$ through variations in the other access service $i$; it is the product of the direct displacement of $I$ by $i$ and of $i$ by $j$. Observe that the denominator of the right hand side of (6) and (7) is the same and equal to $1-\sigma_{j}^{D E} \sigma_{j}^{E D}$ : it measures the impact that modifying the price of one access service $i$ has on the demand for this service, through variations in the demand for the other access service $j(j=\{D, E\}, j \neq i)$. It is composed of the product of the displacement ratio of $i$ by $j$ and the displacement ratio of $j$ by $i$. A high value for this product (close to one) means that any increase in, say, the entrant's access will generate a big decrease in the amount of CDA, which in turn will increase by a lot the amount of the entrant's access. In other words, a high value for this product means an important feedback effect between access products which, other things equal, lessens the negative impact of an access charge increase on the demand for this product and thus increases the value of the optimal access charge.

In terms of comparative statics, the results have the expected sign, with both access charges increasing with all direct displacement ratios $\left(\sigma_{j}^{I E}, \sigma_{j}^{I D}, \sigma_{j}^{D E}, \sigma_{j}^{E D}\right)$. Finally, we 
get back to the Armstrong (2002) formula when $\sigma_{j}^{D E}=\sigma_{j}^{D E}=0$ - i.e., in the case where the demands for the two access goods are independent.

Comparing (4) and (5) when $\lambda=0$ and $w_{j}=1$, it is clear that the optimal value of both access charges in general differ, even if the delivery cost is the same in both cases. In this case, the optimal entrant's access charge is larger than its corresponding CDA level if and only if

$$
\frac{-\partial q_{j}^{I} / \partial p_{j}^{E}}{\partial\left(q_{j}^{D}+q_{j}^{E}\right) / \partial p_{j}^{E}}>\frac{-\partial q_{j}^{I} / \partial p_{j}^{D}}{\partial\left(q_{j}^{D}+q_{j}^{E}\right) / \partial p_{j}^{D}} .
$$

This condition is easy to understand since it compares the overall displacement ratios when the two access charges are increased. More precisely, the left hand side of (8) is the ratio of the derivative of USP E2E demand with respect to the entrant's price, divided by the derivative of total demand for access (by the entrant and CDA) with respect to the entrant's price. It then represents the displacement ratio of USP E2E demand by (any form of) access following variations in the entrant's access charge. The right hand side measures the corresponding displacement when the price of CDA is varied. A higher overall displacement ratio then calls for a larger optimal access charge, for the usual reason.

The third term in (4) and (5) is composed of a Ramsey component multiplied by the same ratio as in (1) and (2). The Ramsey term also becomes more complex. Its denominator is the same as in (6) and (7) and measures the feedback effect between the two access services. The numerator is a weighted sum of inverse elasticities on the two access markets. This is due to the fact that an increase in, say, the entrant's access charge not only impacts the amount of the entrant's access demanded but also, through the displacement of CDA by the entrant's access, the amount of CDA demanded. Hence, the weight put on the inverse elasticity of CDA in the formula for the entrant's access equals the displacement ratio of CDA by entrant's access, $\sigma_{j}^{D E}$.

I now turn to the determination of the optimal value of the retail price $p$. Using (4) 
and (5) in (3) together with $\lambda=0$ and $w_{j}=1$, the optimal $p$ is given by

$$
p=\left(c^{I}+d_{U}^{I}\right) \frac{d q_{U}^{I} / d p}{d q_{U}^{I} / d p+d q_{R}^{I} / d p}+\left(c+d_{R}^{I}\right) \frac{d q_{R}^{I} / d p}{d q_{U}^{I} / d p+d q_{R}^{I} / d p},
$$

where I have used the notation

$$
\frac{d q_{j}^{I}}{d p}=\frac{\partial q_{j}^{I}}{\partial p}+\sigma_{j}^{E} \frac{\partial q_{j}^{E}}{\partial p}+\sigma_{j}^{D} \frac{\partial q_{j}^{D}}{\partial p} .
$$

Equation (9) shows that the USP retail price is a weighted average of marginal costs in the urban and rural markets. The weights used are equal to the share of variation of quantity in one delivery area (when the letter price is changed), $d q_{j}^{I} / d p$, in the total variation in both areas. The variation $d q_{U}^{I} / d p$ is the sum of three elements: the direct impact of $p$ on the USP E2E quantity, as given by the partial derivative $\partial q_{j}^{I} / \partial p$, the indirect impact through variations in the amount of entrant's access (expressed as the product of the partial derivative of entrant's access with respect to $p$, and of the displacement ratio $\sigma_{j}^{E}$ ), and the indirect impact through variation in the amount of CDA.

It is worth noting ${ }^{8}$ that weights are proportional to variation of quantities when the price changes, and not to the absolute value of quantities: it is not the market size that matters, but its sensitivity to variations in the letter price. Moreover, with imperfect substitutes we have that $0 \leq \sigma_{j}^{i} \leq 1$ and $\partial q_{j}^{i} / \partial p>0, i=\{D, E\}$. If we make the reasonable assumption that the direct price effect on $q^{I}$ is larger than the indirect price effect (so that $d q_{j}^{I} / d p<0$ ), we obtain that

$$
\left|\frac{d q_{j}^{I}}{d p}\right|<\left|\frac{\partial q_{j}^{I}}{\partial p}\right|
$$

and the optimal letter price formula puts less weight on area $j$ when access is supplied to this area than if it were not! The reason for this surprising result is the following: Increasing the USP letter price has two effects on area $j$ 's welfare, and they operate in

\footnotetext{
${ }^{8}$ I thank a referee for pointing out that this result is mentioned in Crew and Kleindorfer(1979).
} 
opposite directions. The first, direct, effect is to decrease the number of USP letters. The second effect is to increase the quantity of access (including CDA) demanded. To link these variations in quantities to variations in welfare, note that the access charge formula implies that the access charge is larger than social cost $\left(a_{j}>d_{j}^{I}\right)$ if and only if the USP letter price is greater than total marginal cost for delivery to this area $\left(p>c^{I}+d_{j}^{I}\right)$. Direct and indirect effects on quantities are thus of opposite signs, while markups over marginal cost have the same sign for access and USP retail letter. This implies that the two effects of varying $p$ on welfare go in opposite directions, with the indirect effect mitigating the direct impact. Differences between price and marginal cost are then less damaging for social welfare in the presence of this indirect effect - i.e., when access is offered, and the optimal pricing formula puts a lower weight on markets where access exists.

Finally, since the (uniform) retail price is a weighted sum of marginal costs, and since the (differentiated) access charges simply compensate the USP for profit lost on other markets due to the provision of access, it is highly unlikely that these prices will allow the USP to cover its fixed costs $F$. This means that the USP profit will be binding at the optimum. In that case, the formula in (9) has to be modified in the usual way i.e., by adding a Ramsey term to the right hand side. ${ }^{9}$

Before turning to the numerical simulations of this model, I would like to explore another objective for the regulator. As argued in Panzar (2004), assuming that the regulator chooses policies to provide universal service at the lowest uniform price compatible with break-even may have more practical relevance than assuming welfare maximization. In our setting, this translates into minimizing $p$ while allowing the USP to break-even. This in turn amounts to finding the access charges that maximize USP's profit, subject to the USP breaking even. The intuition for this result is simple: any profit made selling access allows the USP to decrease its retail price. The first order conditions for the ac-

\footnotetext{
${ }^{9}$ The formula obtained in that case does not shed additional light on the problem and is thus omitted here.
} 
cess charges are then given by formulas (4) and (5) in which $w_{j}=0$, which corresponds to the first order conditions for profit maximization. The value of $p$ is given by the break-even constraint $\Pi^{I}=0$. We will study this case in the next section, together with the weighted welfare maximization scenario.

\section{$5 \quad$ Numerical Results}

The theoretical analysis performed above provides optimal access charges and USP E2E price formulas. Unfortunately, the exploitation of first-order conditions does not shed light on the access regime that will emerge in each delivery area (i.e., whether entrants bypass or use access) or on the welfare consequences of this access pattern. With the value of the shadow cost of the profit constraint endogenous, it is also difficult to obtain the impact of, say, a higher weight put on rural consumers on the optimal price levels. Finally, the impact of going from welfare maximization to retail price minimization is impossible to obtain from first order conditions alone. To obtain some insight into these dimensions, I now resort to numerical simulations. Calibration assumptions are summarized in the appendix. They are chosen in order to give a reasonable demand and cost representation of the postal sector in Europe.

The benchmark situation is before liberalization, where the monopoly USP breaks even with a 0.35 euro E2E price and where no access is provided. In order to disentangle the impact of the availability of CDA, the possibility of bypass, and the objective of the regulator, I present four different scenarios. The first one (labeled Case 1 in Table 1) corresponds to the situation where there is no CDA available and no possibility for entrant's bypass (i.e. the entrants have to access the USP network if they wish to deliver in any given area). I then introduce CDA in Case 2, while Case 3 further allows the entrant to bypass USP delivery. In all three cases, the objective of the regulator is to maximize unweighted welfare subject to the USP breaking even. Finally, in Case 4 I show results where the regulator minimizes the USP E2E price in a context where CDA 
exists and bypass is available to entrants.

Comparing Case 1 to the pre-liberalization scenario, we see the beneficial impact of entry alone (i.e., without CDA) when delivery bypass is not an option for entrants. More precisely, the margin made by the USP on selling access contributes to funding its fixed cost and enables it to decrease its E2E price. The consumers in both areas thus benefit in two ways from the opening to competition: because of the availability of a new service offered by entrants, and because the more intensive use of the USP network allows it to lower its price. ${ }^{10}$

Table 1: Simulation Results ${ }^{11}$

\begin{tabular}{|l|c|c|c|c|c|c|}
\hline & & Monopoly & Case 1 & Case 2 & Case 3 & Case 4 \\
\hline Entrant's Access Charges & Urban & - & 0.202 & 0.198 & $>d_{U}^{E}$ & $>d_{U}^{E}$ \\
\hline & Rural & - & 0.230 & 0.227 & 0.292 & 0.294 \\
\hline & & & & & & \\
\hline CDA charge & Urban & & - & 0.215 & 0.244 & 0.266 \\
\hline & & & & & & \\
\hline USP E2E price & & 0.35 & 0.347 & 0.342 & 0.418 & 0.416 \\
\hline & & & & & & \\
\hline Consumer Surplus & Urban & 4.142 & 4.257 & 4.414 & 4.056 & 4.043 \\
\hline & Rural & 0.512 & 0.517 & 0.522 & 0.440 & 0.442 \\
\hline & & & & & & \\
\hline Welfare & & 4.654 & 4.773 & 4.936 & 4.497 & 4.485 \\
\hline Case & & & & &
\end{tabular}

Case 1: No CDA, no bypass, max unweighted welfare.

Case 2: CDA, no bypass, max unweighted welfare.

Case 3: CDA, bypass, max unweighted welfare.

Case 4: CDA, bypass, $\min p$.

Comparing Cases 1 and 2 allows assessment of the impact of introducing CDA in an environment without bypass. We observe the same phenomenon as when we introduce the entrant's product: the availability of a new good, itself of value to the consumers, allows the USP to spread its fixed costs on larger volumes and to decrease

\footnotetext{
${ }^{10}$ Remark that welfare increases notwithstanding the fact that the entrant's upstream cost is higher than the USP's cost $\left(c^{E}=0.13\right.$ euro $>c^{I}=0.1$ euro $)$.

${ }^{11}$ Prices are in euros; consumer surplus and welfare are in billion euros.
} 
its retail E2E price. This provides benefits to both kinds of customers - i.e., even to the rural customers who, by assumption, do not use CDA. Of all cases studied here, the availability of CDA coupled with entry without bypass leads to the highest welfare for consumers.

Case 2 also allows a comparison of the optimal values of the three access charges. I obtain that $a_{R}^{E}>a_{U}^{D}>a_{U}^{E}$. The first inequality is hardly surprising, given that the USP delivery cost is much higher in the rural ( 0.16 euro) than in the urban area (0.07 euro). The second equality can be interpreted in the light of equations (4) and (5). The first two components of both equations are equal since, with our calibration, $\sigma_{U}^{E}=\sigma_{U}^{D}$. The discrepancy between the two urban access charges comes from different demand price elasticities and different displacement ratios between both kinds of access. Both differences conspire to increase the CDA charge compared to the entrant's charge, since the price elasticity is higher for the latter while CDA displaces more of the entrant's letters than the reverse $\left(\sigma_{U}^{E D}>\sigma_{U}^{D E}\right)$. Of course, these differences arise from our calibration assumptions, and the fact that the CDA charge is greater than the entrant's may vary with the assumptions used. My main point is rather that, even when demand as well as cost functions exhibit a large amount of symmetry, the optimal level of both access charges will in general differ. Imposing that both access charges be equal is thus an additional constraint that will result in a lower optimal welfare level. ${ }^{12}$

The only difference between Cases 2 and 3 is that the latter allows the entrants to bypass the USP delivery network. The 0.198 euro urban access charge offered to entrants in Case 2 is greater than the entrant's delivery cost to this area (0.12 euro) so that the entrant will bypass the USP urban delivery network. We assume, as is the case in practice, that the USP is prevented by the regulator from basing its access charge on

\footnotetext{
${ }^{12}$ If one imposes this constraint, the optimal value of the urban access charge (0.204 euro) is in between the values for CDA and the entrant's urban charge reported in Case 2. The introduction of this constraint has the intuitive effect of increasing the other prices as well as $\lambda$ and decreasing total welfare, although with our simulations the latter decreases by a rather small 2 million euros.
} 
the entrant's delivery cost, so that it cannot prevent urban bypass from happening. The entrant uses access to the USP rural delivery network. Compared to Case 2, the USP loses the business of selling entrant's access to the urban area and increases its rural access charge, its CDA price, and its E2E price in order to break-even. On the other hand, urban consumers benefit from the cheaper entrant's good. With our calibration assumptions, the impact of higher USP (retail and CDA) prices on their surplus is bigger than is the impact of the lower entrant's price, and urban (as well as rural) consumers are worse off when bypass is available! We further obtain that total welfare is lower than under monopoly because (inefficient) bypass by entrants forces the USP to increase its prices.

The reader may ask whether this result is specific to our cost assumptions, and what would be happen if the entrant's urban delivery cost were closer to the USP's cost, so that bypass would be less inefficient than in Table 1 . I obtain that total welfare in the presence of bypass (Case 3) actually decreases when the entrant becomes less inefficient at delivering letters in the urban area (i.e., when $d_{U}^{E}$ is lowered from its 0.12 euro level in Table 1)! The reason is that a lower entrant's price brought by a lower delivery cost means stronger competition for the USP on the urban market. This in turn forces the USP to increase its retail as well as access prices in order to recover its fixed costs. The welfare impact of higher USP prices is larger than the impact of the lower entrant's urban price, so that total welfare decreases as the entrant becomes less inefficient! Moreover, if the entrant becomes efficient enough $\left(d_{U}^{E}<0.10\right.$ euro, compared to $d_{U}^{I}=0.07$ euro), it cuts so much into the USP urban volumes that no price combination allows the USP to break even. ${ }^{13}$

Case 4 keeps the same setting as Case 3 (CDA and bypass allowed for entrants), but instead assumes that the regulator minimizes the USP E2E price subject to the USP breaking even. Compared to Case 3, the rural access charge and especially the CDA

\footnotetext{
${ }^{13}$ I obtain the same comparative static results when the entrant's upstream $\operatorname{cost} c^{E}$ is lowered, instead of its urban delivery cost $d_{U}^{E}$.
} 
charge increase, which allows a slight decrease in the USP retail price. Both kinds of consumers lose from this focus on the USP retail price. On the other hand, Cases 3 and 4 do not differ much with our calibration, which means that a regulator maximizing social welfare would set prices close to the levels that minimize the USP E2E price. It may be tempting to use these results as a vindication for the price minimization strategy, on the ground that this strategy is easier to implement -and to explain to regulated entities or to politicians- than is welfare maximization. On the other hand, observe that the USP E2E price in Case 4 is higher than the (regulated) monopoly price. This means that, if a regulator is interested in minimizing the USP retail price, opening the postal market to competition while allowing for bypass results in a worse outcome than the monopoly situation! On the other hand, in the absence of bypass the opening to competition would allow a decrease in the USP E2E price (since it is already lower than 0.35 euro in Cases 1 and 2 when the regulator maximizes welfare). Finally, it is worth mentioning that our analysis abstracts from efficiency considerations. If the opening to competition puts pressure on the USP to be more efficient, it may of course result in higher welfare and/or a lower USP E2E price.

I now turn to the impact of using weights on consumer surplus that differ from the unit weight put on the USP profit when assessing welfare $W$. I first assume that the weight is equal for urban and rural consumers $\left(w_{U}=w_{R}=w\right)$. Whether the USP profit constraint is binding at the optimum or not (when CDA and bypass are allowed) depends on how much weight is put on consumer surplus. If this weight is large enough $(w \geq 0.38)$, the constraint binds at the optimum. In that case, the precise value of the weight does not matter, since any weight greater than this threshold will give the optimal values reported in Case 3 of Table 1. The intuition for this result is straightforward: If the profit constraint is binding, then USP profit is zero, and welfare is composed only of consumer surplus at the optimum. The weight that is put on this surplus then acts only as a multiplicative constant, which does not affect the results. On the other 
hand, weights lower than 0.38 do affect the result, with a lower weight meaning that the regulator gets closer to pure profit maximization. I obtain very intuitively that all price levels increase monotonically as the weight put on consumer surplus decreases from 0.38 towards zero. ${ }^{14}$

When weights differ between rural and urban consumers, I obtain that increasing the weight put on one kind of consumers results in a decrease in the access charge paid to deliver to this consumer (the entrant's charge for rural consumers, CDA for urban ones), an increase in the charge paid to deliver to the other area (because of the USP profit constraint), and an increase in the shadow cost of the profit constraint. On the other hand, the impact on the USP retail price is not symmetrical, since this price decreases when more weight is put on rural consumers, while it increases when urban consumers' surplus receives a higher weight. In other terms, the optimal way to please rural consumers is to decrease both the entrant's rural access charge and the USP retail price (at the expense of urban consumers, in the form of a higher urban CDA charge) while pleasing urban consumers occurs only through reductions in the urban CDA charge, with increases in the USP retail price and rural entrant's charge allowing the USP to break even.

\section{Conclusion}

This paper has developed a theoretical model of access pricing that incorporates three main characteristics of the postal sector: the ability of entrants to bypass the incumbent's delivery network, the imposition of universal service obligations (including uniform pricing) on the incumbent but not on entrants, and the presence of customers' direct access. I compute the optimal access charges and $\mathrm{E} 2 \mathrm{E}$ price formulas and comment on them. I also study what drives the differences between the optimal CDA and

\footnotetext{
${ }^{14}$ Profit maximizing prices are 0.349 euro for rural access, 0.296 euro for urban CDA and 0.490 euro for the USP retail price. The maximum profit for the USP is 97 million euros.
} 
entrant's access charges, and I make explicit the link with the optimal uniform retail price. The numerical simulations show that the welfare maximizing setting is the one suggested by Panzar (2004), where both access products are offered but where bypass is not allowed.

The results I obtain here are closely linked to the set of available instruments. For instance, in our setting with fixed coefficients between output and inputs, an output tax on the entrant would be much better from a welfare viewpoint than the implicit tax on access I study, since it would not give the entrant incentives to bypass the USP delivery network inefficiently. Such output taxes are not used in the postal sector (unlike in the telecommunications sector, where they are often used to finance a universal service fund), so I have left them out of the picture.

I suggest three ways to improve on this model. A first extension would allow for imperfectly competitive entrants. In the likely case where entrants are not directly regulated, the access charges and USP E2E price would acquire a new objective: to induce a lower entrant's price. The direction in which access charges and E2E price should be modified would then depend on the reaction function of entrants (whether the USP and entrant's instruments are strategic substitutes or complements) as well as on the necessity for the USP to break even. Second, I have introduced CDA as a third good, without developing the micro-decisions of the many customers, differing in preparation cost, who decide whether to buy an E2E or an access-based product. My approach can be considered as a reduced form of a more micro-based model, but a full treatment of this decision, as in Billette et al. (2003a), would be more satisfactory. Third, and more important, I have assumed that the entrant's good is essentially the same whether the entrant delivers itself or uses access to the USP network for delivery. In other words, all the differentiation between the entrant's and USP's mail products comes from collection, sortation, and transportation activities. The analysis would gain in realism if this assumption were relaxed. 


\section{Appendix}

Calibration assumptions are inspired from De Donder et al. (2004). The (quasilinear) utility function of all senders is quadratic so that demand functions are linear in their three arguments. I start by calibrating the parameters related to the USP retail good in order to obtain that the total quantity sold by the USP under monopoly at an assumed current price $p$ of 0.35 euro is 8,900 million items for urban delivery and 1,100 million items for rural delivery. I also impose that both demand functions exhibit a direct price elasticity of -0.376 in both markets at the 0.35 euro price.

I assume that rural consumers do not use CDA, so I set to zero the parameters related to the CDA good in their utility function. I make the following two assumptions in order to calibrate the parameters related to the entrant's good. First, the entrant would obtain a $10 \%$ market share if it were to offer its good at the same 0.35 euro price as the incumbent. Second, each letter sold by the entrant displaces $0.75 \mathrm{E} 2 \mathrm{E}$ letter previously sold by the incumbent.

I assume that there are two kinds of urban customers: large ones who use CDA and smaller ones who do not. Demand is calibrated in such a way that each kind of customer represents exactly half the total urban market when all goods are priced at 0.35 euro. I then calibrate the large urban consumers' utility function, and I obtain the utility function of the small urban consumers by setting to zero the parameters related to CDA. I use three assumptions in this calibration. First, the entrant would obtain a $10 \%$ market share if all three goods were priced at 0.35 euro. Second, the CDA share of USP volumes (E2E service plus CDA) would be 30\% if CDA were 10\% cheaper for the large customers than the other two goods. Finally, without any indication that one displacement ratio should be lower or larger than another, I have assumed that $\sigma_{L U}^{D E}=$ $\sigma_{L U}^{E D}=\sigma_{L U}^{I E}=\sigma_{L U}^{I D}=0.4$. Note that these displacement ratios are computed for the large urban customers (hence the subscript $L U$ ). When large and small customers are lumped together to obtain the urban demand for mail, I obtain that $\sigma_{U}^{E D}=\sigma_{U}^{I D}=0.4$, 
$\sigma_{U}^{D E}=0.21<\sigma_{U}^{I E}=0.51$. The displacement ratio of CDA by the entrant's good is lower in the total urban market than in the subset of large customers who use CDA because small customers do not use CDA. The opposite pattern holds for the displacement of the USP retail good by the entrant's good. Finally, with these calibrations I obtain that $\sigma_{U}^{E}=\sigma_{U}^{D}=0.65$.

Regarding the USP costs, the fixed cost $F$ is set at 1,700 million euros. The collection plus transportation and sortation unit cost is $c^{I}=0.1$ euro for the USP and the unit delivery cost is $d_{U}^{I}=0.07$ euro on the urban market and $d_{R}^{I}=0.16$ euro on the rural market. The reader can easily check that the USP breaks even at the 0.35 euro price before the opening of the market to competition. The entrant does not face a fixed cost but has higher marginal costs than the USP on both markets: $c^{E}=0.13$ euro, $d_{U}^{E}=0.12$ euro and $d_{R}^{E}=0.35$ euro. The preparation cost for customers resorting to CDA (denoted by $k$ ) is 0.08 euro.

\section{Acknowledgements}

I thank Helmuth Cremer, Frank Rodriguez, the editor and two referees for their most valuable comments, as well as participants to the Third International Conference on Applied Infrastructure Research hosted by the Berlin Institute of Technology. I bear full scientific responsibility for the content of this paper, including any remaining error.

\section{References}

[1] Armstrong, M. (2001), "Access Pricing, Bypass, and Universal Service", American Economic Review, AEA Papers and Proceedings, 91, 2, 297-301.

[2] Armstrong, M. (2002), "The theory of access pricing and interconnection", in Handbook of Telecommunication, vol 1., edited by M. Cave et al., 295-386.

[3] Armstrong, M., C. Doyle and J. Vickers (1996), "The access pricing problem: a synthesis", Journal of Industrial Economics, 44, 131-150. 
[4] Billette de Villemeur, E, H. Cremer, B. Roy. and J. Toledano (2003a), "Optimal pricing and global price-cap in the postal sector", Journal of Regulatory Economics, 24, 49-62.

[5] Billette de Villemeur, E, H. Cremer, B. Roy. and J. Toledano (2003b), "Access and (non-)uniform pricing in the postal sector" in Competitive Transformation of the Postal and Delivery Sector, edited by M. A. Crew and P. R. Kleindorfer, Boston : Kluwer Academic Publishers, .

[6] Billette de Villemeur, E, H. Cremer, B. Roy. and J. Toledano (2004), "Worksharing, pricing and competition in the postal sector" forthcoming in Regulatory and Economic Changes in the Postal and Delivery Sector, edited by M. A. Crew and P. R. Kleindorfer, Boston : Kluwer Academic Publishers, 139-162.

[7] Cazalda, J. (2005), "Worksharing and access discounts in the postal sector with asymmetric information", forthcoming in Journal of Regulatory Economics.

[8] Cazals C., F. Fève, Florens JP. and B. Roy (2004), "Delivery Costs II. Back to Parametric Models" forthcoming in Regulatory and Economic Changes in the Postal and Delivery Sector, edited by M. A. Crew and P. R. Kleindorfer, Boston : Kluwer Academic Publishers, 189-202.

[9] Crew M. and P. Kleindorfer (1979), Public Utility Economics, MacMillan Press Ltd, London and St. Martins Press, New York.

[10] Crew M. and P. Kleindorfer (2002), "Balancing access and the universal service obligation", in Postal and Delivery Services: Delivering on Competition, edited by M. A. Crew and P. R. Kleindorfer, Boston : Kluwer Academic Publishers, 3-32.

[11] De Donder P., H. Cremer and F. Rodriguez (2004), "Access Pricing in the Postal Sector: Results from a Model with Bypass and Customer Direct Access", in Regu- 
latory and Economics Changes in the Postal and Delivery Sector, edited by M.A. Crew and P.R. Kleindorfer, Boston: Kluwer Academic Publishers, 163-188.

[12] Economides N. and L. White (1995), "Access and Interconnection Pricing: How Efficient is the "Efficient Component Pricing Rule"?", Antitrust Bulletin, 40:3, $557-579$.

[13] Laffont, J.J. and J. Tirole (2000), Competition in Telecommunications, MIT Press, Cambridge MA.

[14] Panzar, J. (2002), "Reconciling competition, downstream access and universal service and universal service in postal markets", in Postal and Delivery Services: Delivering on Competition, edited by M. A. Crew and P. R. Kleindorfer, Boston : Kluwer Academic Publishers, 93-115.

[15] Panzar, J. (2004), "Combining liberalization and unbundling policies in postal markets", mimeo Northwestern University and University of Auckland.

[16] Rogerson, C. and W. Takis (1993), "Economies of scale and scope and competition in postal services", in Regulation and the Nature of Postal and Delivery Services, edited by M. A. Crew and P. R. Kleindorfer, Boston : Kluwer Academic Publishers. 